\title{
AC 2009-2059: DEVELOPMENT OF AN ASSESSMENT PROCEDURE FOR INTEGRATION OF MATHEMATICAL AND CAE TOOLS IN ENGINEERING COURSES
}

\section{Raghu Echempati, Kettering University}

Dr. Echempati is a Professor of Mechanical Engineering at Kettering University, Flint, MI. His area of expertise is Design and CAE. He is a member of ASME, SAE and ASEE.

\section{Enayat Mahajerin, Saginaw Valley State University}

Dr. Mahajerin is a Professor of Mechanical Engineering at Saginaw Valley State University, Saginaw, MI. His area of expertise is Computational Mechanics. He is a member of ASME.

\section{Anca Sala, Baker College}

Dr. Sala is an Associate Professor and Chair of the Mechanical Engineering Department at Baker College in Flint, MI. She is actively involved in teaching and developing engineering curriculum, and leads the ABET accreditation activities in the department. She is a member of ASEE, ASME, and OSA. 


\title{
Development of an assessment procedure for integration of mathematical and CAE tools in engineering courses
}

\begin{abstract}
In a previous study ${ }^{1}$ the authors presented the teaching and learning experiences of integrating mathematical and $\mathrm{CAE}$ tools in three example undergraduate engineering courses taught at three different universities by three different instructors who share similar teaching philosophies. Integration of mathematical tools such as MATLAB, MathCAD, and Excel, and the CAE packages such as Unigraphics ${ }^{2}$ are found to be very effective teaching and learning strategies for better understanding of the relevant course material where such tools can be incorporated. The three example courses are: Machine Component Design, (taught at Kettering University using Excel and other CAE/FEA tools), Computational and Experimental course (taught at Saginaw Valley State University using MATLAB), and Dynamic Systems and Controls (taught at Baker College using MathCAD). All these are 4-credit courses. The outcome of the previous study proved to be useful as evidenced by the student performance in these courses.
\end{abstract}

Based on the experiences of the previous studies, in this paper an assessment procedure is developed to study its impact on the early implementation of those tools from the beginning of teaching of these same courses as mentioned above. One of the measures of the effectiveness of the developed assessment procedure utilizes the overall performance of the students in those courses. It is hoped that such a procedure can be used to enhance the teaching and assessment of these or other similar courses.

\section{Introduction}

The following sections outline the teaching and assessment experiences of three different instructors in three separate courses. Based on the focused idea of using teaching tools, preliminary assessment procedure is suggested. There are numerous studies conducted in this direction by many researchers ${ }^{3}$, for example, papers presented in ASEE-IEEE Conferences.

\section{Course 1: Machine Design I (Taught at Kettering University)}

\section{Course Description:}

This course is a first course in Mechanical Component Design with pre-requisites of Mechanics of Materials and Statics. Pre-requisite knowledge test in Statics is given at the beginning of the course to reinstate the importance of understanding of free body diagrams. Thus, the Machine Design course deals more with application of the theory and concepts learned in the mechanics sequence, namely, equilibrium of rigid bodies and free body diagrams to design and/or to select mechanical components. Design standards (such as ANSI, AGMA, etc.) are used in depth in this course and the students are advised to adhere to these standards while designing the components. They are also expected to use 
online catalogs and other resources to collect any data that may not be available in the prescribed textbook (for example, material data, or dynamic load ratings for rolling contact bearings). This prepares the students to look for data that may not be readily available in the textbooks ${ }^{4-7}$, which is usually what is expected in a capstone course. Finally, the students are encouraged to attend any technical lectures arranged on campus through professional societies and other student bodies and submit a report, or expected to read and discuss current design topics in the class. These are usually done for some extra credit.

In order to assess a student's pre-requisites knowledge it may be a good idea to collect each student's performance in Statics and Solid Mechanics. However, this may only serve as a general guide since there are many variables involved, namely, who taught those courses, what their grading policies were, and if the grading was 'easy' or 'hard', or 'curved', and finally, what the students' priorities were in learning those courses and how important they felt or realized that those courses build on each other. However, there may be some value in knowing beforehand how well each student performed in those classes in order to take any corrective actions in the Machine Design course. Also, prerequisites knowledge test is very helpful to assess their concepts and to conduct any extra help sessions.

Conventional teaching methods (lectures, classwork and team-home work, mini- and term-ending projects) are followed for this course. The final take-home project enhances the students' understanding of the material covered in the entire course. Also it demonstrates the type of study and research required for realistic design.

Besides a review of the mechanics concepts, perhaps the only two new topics that are usually covered in depth in a typical Machine Design course are: Fatigue Design and (Static and Fatigue) Failure Theories as applied to the design of components (shafts, keys, couplings, fasteners, bearings, springs and gears. Engineering ethics is also introduced to the students.

\section{Course Learning Objectives (CLO's)}

1. Develop, set-up, and solve mechanical component design problems based upon given data and requirements

2. Develop corrective action (define the cause for a problem and the design fixes) for field problems

3. Recognize the need for proper design actions via discussions of current, news worthy, design-related incidents

4. Through mechanical component design class/homework and team-based problems, develop an appreciation for design standards, design tools and the everchanging materials, processing and analytical techniques available to design while providing an understanding of the basics of design 


\section{Assessment Tools used and their effectiveness:}

Several assessment tools are used to understand their effectiveness on the students' performance in the class. In-class problems are found to be very effective to judge if the students' followed the lecture material just in time. Although a few students had problems with this methodology (mostly because of their lack of enough pre-requisites knowledge), many students liked this approach. Group homework is also assigned to reinforce and to retain the concepts learned and used just in time in the classwork problems. In addition to the midterm tests, one comprehensive final (group) project is assigned. Statics pre-requisite knowledge test administered by xxx is also used to analyze students' understanding of freebody diagrams, friction, etc. Also an optional comprehensive final exam is given to them as an opportunity to improve their scores on the midterm tests (best 2 out of 3 exams).

The final project deals with designing a small subsystem consisting of a pulley and a gear mounted on a shaft supported on two bearings. It is the same project with many variations as the previous term's/years' final project. The stepped shaft is to be designed based on static and fatigue loading due to loads from the gear and the pulley, design of keys, coupling, selection of rolling contact bearing at one support, design of journal bearing at the other support, selection of pillow blocks and fastener design based on fatigue loading, bending fatigue and contact stress analysis of the gear teeth, and finally, 'fitting them all together'. Excel/MathCAD/Maple has been used in the calculations. Design standards (ANSI, SAE, AFBMA, AGMA, etc.) have been used while designing each component. Only the power and speed limits of the system are specified, leaving everything else open-ended. Students are expected to start with an application in mind that uses a similar subsystem, and justify all the subsequent assumed data, including the safety factors. This produced several alternative designs that the instructor can use as numerous worked examples for future classes. Each design report can serve as a case study that includes the math and CAE tools they used for the project. Conventionally, many capstone design classes use this approach. However, to a smaller scale, this idea serves the same purpose as a capstone course. Several other alternative inputs may be specified rather than input power and rpm.

Although the students found it easier to design individual components, many of them found it interesting and challenging to put them all together as a subsystem. They realized that if they change any variable that it can affect other parts and thus the entire system. Therefore, while using a math tool such as Excel, they needed to relate all equations using variable names rather than assuming a numerical value of a variable inside an equation. Design charts are also produced that will change instantaneously if a variable associated with any component's design equation is changed. As in the previous years, the entire course work (classwork, homework, quizzes, exams and project) closely followed the course learning objectives (CLOs) identified for this course as stated previously in this paper.

\section{Development of assessment procedure}

In order to develop an assessment procedure, assessment tools need to be identified. Then the data need to be collected from each assessment tool to see how and to what extent 
they map in to the CLOs and the Program Outcomes (POs). For this course, the CLOs and their mapping to the POs has already been identified. Overall, the course syllabus and the course objectives are met to a great extent. As mentioned before, several assessment tools have been identified such as classwork/homework, quizzes/exams and projects. Sincere attempt is made to refer to the CLOs while designing the contents of the assessment tools used. For example, each exam question clearly stated the concept being tested in that question, and to what extent that question addresses the CLO(s) and how it maps the $\mathrm{PO}(\mathrm{s})$. Students were informed where this information will be used. The stated $\mathrm{CLO}(\mathrm{s})$ is/are assumed to be satisfied based on their achieving a certain grade on that question. This is repeated for all assessment tools used in this course, particularly for the final project, in which the students used math and CAE tools to a great extent. At first, it looks like there is a lot of work involved in this exercise, but perhaps at a course level assessment, this may serve as a valuable and an acceptable procedure. Depending on the performance of the student group in a particular term, individual grade weightage on each assessment tool used can be changed for future terms. For example, the final project grade for this course has been reduced from $15 \%$ from previous years to around $10 \%$ based on the current students' overall performance in the class.

Assessment of Final Examination: The students' performance on questions 1 to 3 on the final exam (taken by only 18 students wishing to improve their grade from midterm exams) was below average indicating that those students still lack an understanding of the concepts tested in those questions. This is shown in the first chart. Question 1 requires determination of support reactions to calculate the dynamic load rating of rolling contact bearings, while question 2 dealt with shaft design from static and fatigue considerations, while question 3 was concerned with fatigue design of fasteners. The score on each question was out of 10 points, while question 4 covered the gear tooth analysis concepts.

The overall students' performance shown in the second sample chart indicates an average level. The total number of students in the class was around 85 (in 2 sections). The overall performance on the final project was just about average since grade weightage for final project is only $10 \%$ compared to the rest of the assessment tools used (quizzes, mini projects, etc). Being the final project, when once submitted, the students do not get any time or chance to review and to correct any deficiencies in their work. The overall average grade on the Final Project was around $86 \%$. However, the student feedback (reported in the form of learning outcomes) on the final projects has been very good since it is an assimilation and application of all the concepts learned in the class. Sample students feedback on the final project was presented in the previous paper and their comments generally remain similar in all these years it was taught by the author.

Generation of Course Assessment Report: one of the ideas for assessment may be to generate a term by term summary report of the assessment data collected during a particular term. This is developed based on a meeting of the instructor with all faculty generally involved in teaching this course. The report among the other details contains the identified deficiencies of the concepts and the difficulties faced by the students and the planned actions for continuous improvement. For example, offering help sessions, or including recitation period to the course credits (for example, 3 hours of lecture instead of 4 hours, with 1 or 2 hours of mandatory recitation periods to solve problems). The 
summary report also serves as an evaluation and assessment tool for ABET purposes. The summary report may also contain charts showing the students' performance or a final course grade. An example summary document is shown below.

\section{Sample Course Assessment Summary Report}

Course Number/Name:

Instructor:

Course Coordinator:

Assessment Term/Year:

Group Meeting Date:

Attendees:

Brief Summary of Assessment Results:

Recommended Action Items for Continuous Improvement:

Plan of action in the next term:

Plan of action for the current assessment year:

Students' performance chart for the term/year:
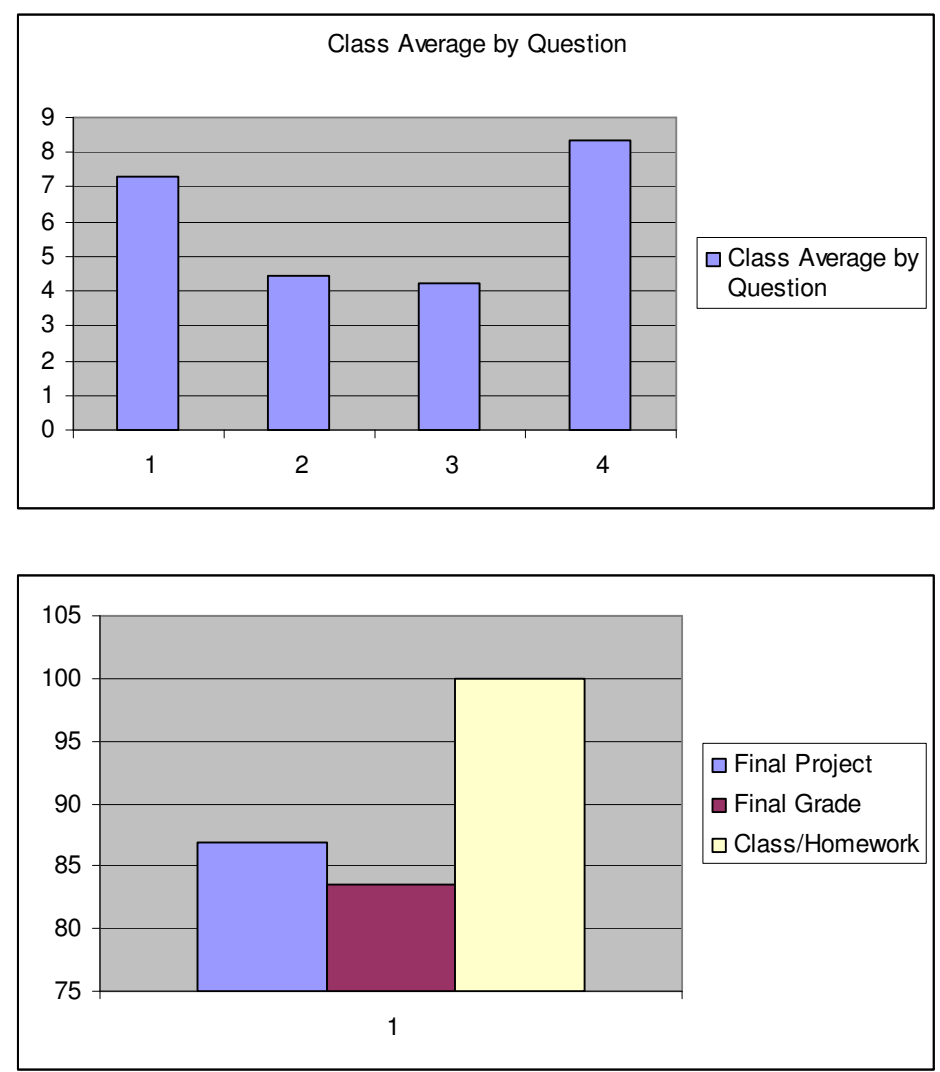

The next section deals with development of assessment data and discussion for the second course on Computational \& Experimental Method. 


\section{Course 2: Computational \& Experimental Method (Taught at Saginaw Valley State University)}

\section{Course Learning Objectives (CLOs):}

1. Develop mathematical models for engineering problems

2. Develop an understanding of contemporary numerical methods

3. Learn computer programming using MATLAB $^{8}$ and MINITAB

4. Conduct experiments, collect data, apply statistical methods and develop mathematical models for the data

\section{Assessment of the Pre-requisites Knowledge:}

During the first lecture a survey was distributed to recognize student academic background and skills. There were 14 students enrolled in the course and their responses appear in Table 1. Numbers of responses are in the parenthesis.

Table 1: The Student Survey

\begin{tabular}{|l|l|}
\hline \multicolumn{1}{|c|}{ Topics } & \multicolumn{1}{c|}{ Responses } \\
\hline Academic Standing & Junior (8), Senior (6) \\
\hline Mathematics Level & Completed: Calc. II (4), Calc. III(10) \\
\hline Computer Programming Skills & No or Minimum Skills (10), One Language(4) \\
\hline Engineering Courses & Completed Dynamics (2), Beyond Dynamics (12) \\
\hline
\end{tabular}

\section{Measurable Performances:}

The result of the survey in Table 1 helped the Instructor to formulate the course content and also the content for each of the following measurable performances:

1. Homework

2. Lab Projects

3. Team Projects

4. Exams

\section{Assessments:}

During the semester the ability that each student was expected to develop by taking the course was measured using the responses from each student to the measurable performances. To assess students understanding of the topics including items 1-4 in the course objectives, appropriate questions including open-ended ones were incorporated into each of the measurable items. Evaluated performances of each student highlighted their areas of strengths and weaknesses. Instructor communicated these to each student 
confidentially during the weekly office hours. The overall information was explained to the students at the next class session. A correction scheme was developed which included additional in-class examples related to the areas of weaknesses. Before the Final Exam, a summary of the up-to-date grades was made available for students' inspection. Following the Final Exam, the overall course grade including a summary of grade statistics was posted.

Highlights of the outcomes from each of the measurable items are as follows:

Homework: Generally, students did well in the homework assignments because of the ample time and the opportunity to use the Instructors' office hours to ask questions. Few students had difficulties with computing errors and root mean squares (rms) in multivariate functions. The instructor corrected that by giving additional examples and using both Taylor series and the total derivative concepts.

Lab Projects: Students' performance in the lab projects was satisfactory except in the area of algorithm writing. This was because many students did not have sufficient background in programming. A correction plan consisted of algorithm design during the weekly workshop sessions was used. During the workshop students were required to develop algorithms related to engineering topics such as kinematics and structural problems.

Team Projects: Two comprehensive team projects were assigned. The first one was in the area of material strength and variation of material properties versus composition, time, and temperature. The second project was related to fluid flow in an open system. In these projects students were required to use material science, phase diagrams, and fundamentals of thermodynamics. They were also required to different units (English and SI units). A result for each project was highly satisfactory because students observed good correlation between the theory and experiment. In addition, student teams conducted statistical techniques including error analysis, regression, and the t-Test. The main reasons for successes in these Team Projects were:

- Students collected data on their own,

- Students had sufficient background in related courses (based on the initial survey),

- Majority had good hands-on skills,

- Ample time (about two weeks) was provided to complete each project,

- Sufficient theoretical modeling corresponding to each project was covered in the lecture notes.

Exams: Student grades in the Exams were the main source of information to assess their understanding achievements in the goals. Besides poor management of the time, lack of success by those who did not do well was mainly because of poor skill in mathematical topics including manipulation of multivariate functions, improper integrals, and multiple integrals. Future lectures related to these topics are intended to correct these difficulties. 


\section{Data Collection and Analysis of the Results:}

Table 2 shows data collected for each assessment tool and the student performance in each category. The Table also shows the corresponding statistical parameters for each assessment tool.

Table 2: Statistical Results on Percent Basis

(Number of Students: $n=14$ )

\begin{tabular}{|l|l|l|l|l|l|}
\hline Item & Min. & Max. & Range & Mean & Std. Dev. \\
\hline Homework & 53 & 97 & 44 & 87.2 & 11.6 \\
\hline Computer Projects & 89 & 98 & 9 & 95 & 2.8 \\
\hline Team Projects & 40 & 100 & 60 & 87 & 14.8 \\
\hline Exam 1 & 68.5 & 95.5 & 27 & 84.8 & 7.3 \\
\hline Exam 2 & 49 & 91 & 42 & 72 & 19.7 \\
\hline Final Exam & 50 & 93 & 43 & 71.9 & 24 \\
\hline Overall & 55.5 & 91.1 & 45.6 & 80.8 & 11.5 \\
\hline
\end{tabular}

Letter Grades: $\mathrm{F}(2), \mathrm{D}(0), \mathrm{C}^{+}(1), \mathrm{B}-(1), \mathrm{B}(4), \mathrm{B}^{+}(1), \mathrm{A}^{-}(2), \mathrm{A}(3)$

\section{The Percentile}

The $\mathrm{P}^{\text {th }}$ percentile of the overall course grade, $\mathrm{G}$, was evaluated by sorting $\mathrm{G}$ from low to high. A desired $\mathrm{P}^{\text {th }}$ percentile was obtained by $(\mathrm{n}+1) * \mathrm{P}$. For $\mathrm{n}=14$ students the $25^{\text {th }}, 50^{\text {th }}$ and $70^{\text {th }}$ percentiles were:

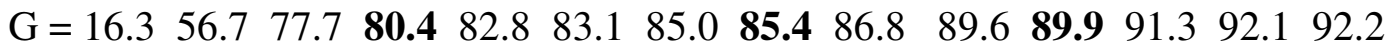

For the $25^{\text {th }}$ percentile we selected $0.25 *(n+1)=3.75$ or roughly 4 observations. This value corresponds to 80.4 . The grades show 10 observations larger than 80.4 , and three observations smaller than 80.4 . The $50^{\text {th }}$ and $70^{\text {th }}$ percentiles were evaluated similarly:

$50^{\text {th }}$ Percentile $=7.5$ or roughly 8 observations corresponding to $85.4 \%$. This corresponds to: six grades larger than, and five grades smaller than $85.4 \%$, respectively.

$70^{\text {th }}$ Percentile $=10.5$ or roughly 11 observations corresponding to $89.9 \%$. This corresponds to: three grades larger than, and 10 grades smaller than $89.9 \%$, respectively.

Many others educational research papers have been presented in ASEE Conferences ${ }^{9-11}$ on the effective integration of math and CAE tools in engineering courses. These and 
other research findings confirm that this is one of the ways to improve student's motivation and critical thinking skills to improve their performance in the engineering courses.

The final section presented below discusses observations from yet another course taught at a different college. The overall conclusions based on the experiences of teaching and assessment of these three courses is presented at the end of the paper with a preliminary suggested assessment procedure.

\section{Course 3: Dynamic Systems and Control (Taught at Baker College)}

This course is a 4-credit hour senior level course, taught to undergraduate Mechanical Engineering students at third author's institution. Details about the course are given in a

previous paper ${ }^{1}$. The format is lecture-based supplemented by computer simulation sessions using MathCAD, and a required design project including transient and steadystate analysis of the chosen system.

The Course Learning Objectives are called Student Learning Outcomes (SLOs) at this school. These are:

1. Distinguish between open-loop and closed-loop control systems, their designs and applications

2. Apply Laplace Transform and Inverse Laplace Transform to solve problems involving mathematical modeling of control systems

3. Use transfer functions and impulse-response functions to model control systems

4. Use block-diagrams to represent control systems

5. Use state-space representation to describe control systems

6. Apply mathematical modeling to solve problems involving control of mechanical, electrical, and fluid systems

7. Perform transient-response analysis to solve problems involving control of first and second order dynamic systems

8. Apply Routh's stability criterion to model and optimize control systems

9. Complete a course project involving topics of the course and transient and steadystate response analysis of the control system

MathCAD, used in this course, allows users to solve a wide range of scientific problems, in symbolic or numeric form. It easily generates plots and reports. As the Dynamics Systems and Control course is highly mathematical, MathCAD is a very valuable resource for students to save time on intensive computations. It allows the instructor to focus on the concepts and principles of control systems, and students to be able to solve more sophisticated problems which might be difficult to attack otherwise. Out of the course SLOs MathCAD supports specifically achievement of SLOs 2, 3, 7, and 9. At this point one has to note that MathCAD is not the only computational software that can be used for this course. More popular than MathCAD is the MATLAB software, the use of which was described in this paper in relation to Course 2, Computational and Experimental Method. At third author's institution MathCAD has been used historically 
in a number of engineering courses. However, the department is now transitioning to MATLAB, which will be used next time Dynamics Systems and Control will be taught. Even though the specific functions and programs are different in the two software packages, the positive effect on student learning in the course is similar with both.

\section{Assessment Tools and Analysis of Results}

The tools for direct assessment in the course include weekly homework $(\mathrm{H})$, weekly quizzes $(\mathrm{Q})$, midterm exam $(\mathrm{M})$, final exam $(\mathrm{F})$, and design project $(\mathrm{P})$. The student population from the 2007-08 academic year consisted of 8 students. The Table below shows the achievement of each student in each category, as well as the class average.

Table 3: Individual student performance and class average in the five assessment categories

\begin{tabular}{|l|r|r|r|r|r|r|r|}
\hline Student & HW & Q & M & F & P & \multicolumn{1}{l|}{ Total } & \multicolumn{1}{l|}{ \% } \\
\hline 1 & 99 & 93 & 81 & 98 & 95 & 466 & 93.2 \\
\hline 2 & 99 & 94 & 85 & 90 & 100 & 468 & 93.6 \\
\hline 3 & 69 & 90 & 60 & 77 & 100 & 396 & 79.2 \\
\hline 4 & 55 & 93 & 53 & 74 & 90 & 365 & 73 \\
\hline 5 & 67 & 90 & 73 & 69 & 100 & 399 & 79.8 \\
\hline 6 & 99 & 89 & 83 & 97 & 100 & 468 & 93.6 \\
\hline 7 & 94 & 93 & 95 & 100 & 100 & 482 & 96.4 \\
\hline 8 & 71 & 90 & 81 & 84 & 85 & 411 & 82.2 \\
\hline Mean & $\mathbf{8 2}$ & $\mathbf{9 2}$ & $\mathbf{7 6}$ & $\mathbf{8 6}$ & $\mathbf{9 6}$ & $\mathbf{4 3 2}$ & $\mathbf{8 6 . 4}$ \\
\hline St. Dev. & $\mathbf{1 8}$ & $\mathbf{2}$ & $\mathbf{1 4}$ & $\mathbf{1 2}$ & $\mathbf{6}$ & $\mathbf{4 4}$ & $\mathbf{8 . 8}$ \\
\hline Median & $\mathbf{8 3}$ & $\mathbf{9 2}$ & $\mathbf{8 1}$ & $\mathbf{8 7}$ & $\mathbf{1 0 0}$ & $\mathbf{4 3 9}$ & $\mathbf{8 7 . 7}$ \\
\hline
\end{tabular}

Very noticeable is the excellent students' performance on the design project, exceeding the performance in any other category. The use of MathCAD in solving for the system output versus time, iterating to optimize the system behavior, and graphing the results in a meaningful way was very helpful for students. A small portion of the project grade (10\%) was contributed by student presentation of his/her project to the entire class during the last class session. At the other end was the students' performance on the in-class Midterm exam. The homework presented some difficulties to some students; however the quizzes went very well. In general the quizzes were based on less difficult, shorter problems than the homework, in order not to take a long time out of the class.

An analysis of SLO achievement in the course based on all graded assignments has been undertaken by the instructor using an Excel spreadsheet to keep track of performance broken down by SLO. Similar analyses were described in previous ASEE papers ${ }^{12,13}$. For brevity we present here in Table 4 results from the Final Exam only. For each SLO assessed an average score of $70 \%$ or better is considered satisfactory achievement. 
Table 4: Final Exam results for individual SLO's

\begin{tabular}{|l|r|r|r|r|r|r|}
\hline Student & \multicolumn{1}{|l|}{ SLO3 } & \multicolumn{1}{l|}{ SLO4 } & \multicolumn{1}{l|}{ SLO5 } & \multicolumn{1}{l|}{ SLO6 } & \multicolumn{1}{l|}{ SLO7 } & \multicolumn{1}{l|}{ SLO8 } \\
\hline Max score & $\mathbf{6 0}$ & $\mathbf{4 0}$ & $\mathbf{6 0}$ & $\mathbf{2 0}$ & $\mathbf{6 0}$ & $\mathbf{4 0}$ \\
\hline 1 & 58 & 40 & 60 & 18 & 60 & 37 \\
\hline 2 & 55 & 40 & 56 & 20 & 60 & 20 \\
\hline 3 & 49 & 24 & 42 & 18 & 42 & 40 \\
\hline 4 & 53 & 38 & 48 & 17 & 32 & 18 \\
\hline 5 & 24 & 22 & 52 & 18 & 42 & 35 \\
\hline 6 & 59 & 40 & 60 & 18 & 60 & 35 \\
\hline 7 & 60 & 40 & 60 & 20 & 60 & 40 \\
\hline 8 & 56 & 32 & 48 & 20 & 47 & 33 \\
\hline Average & $\mathbf{5 2}$ & $\mathbf{3 5}$ & $\mathbf{5 3}$ & $\mathbf{1 9}$ & $\mathbf{5 0}$ & $\mathbf{3 2}$ \\
\hline Percent ave. & $\mathbf{8 6}$ & $\mathbf{8 6}$ & $\mathbf{8 9}$ & $\mathbf{9 3}$ & $\mathbf{8 4}$ & $\mathbf{8 1}$ \\
\hline
\end{tabular}

Gathering data such as the one above over more than one year provides faculty with a long term view of student learning in the course. The figure below shows the comparison of SLO achievement based on Final Exam in two consecutive years, 2006-07, and 200708 . The results are consistent for the two years, even though the student population was small in both years, 3 students in 2006-07, and 8 students in 2007-08. SLO6, which was not assessed in the Final Exam in 2006-07, has been added in 2007-08.

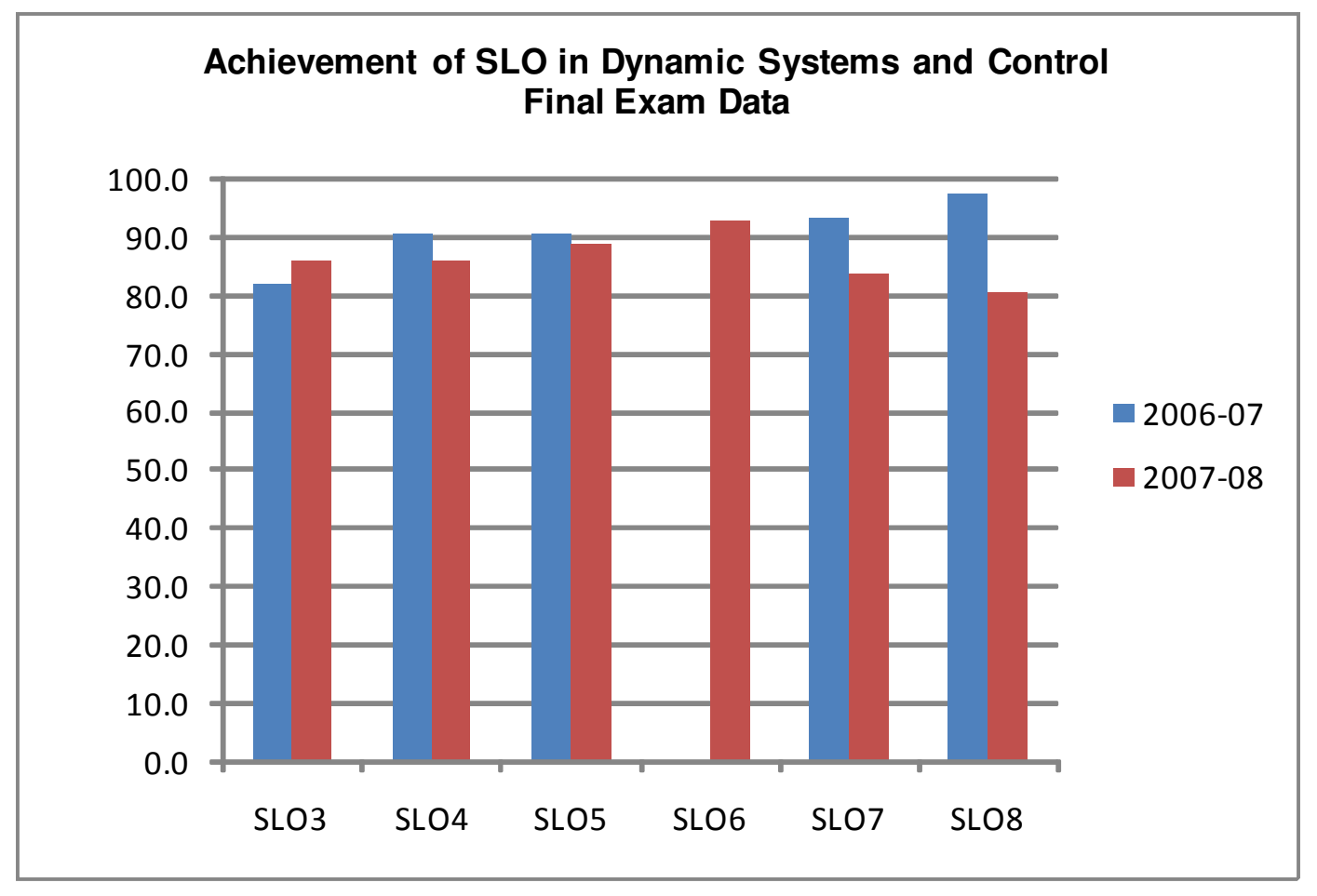

Figure 1: Final Exam data showing achievement of SLO in two consecutive academic years

The systematic method of assessment presented in the paper allows faculty to satisfy the requirements of ABET accreditation, and is a useful tool to improve their teaching. 
It can be noted from the above three sections that it is possible to develop a preliminary assessment procedure that is measurable. The assessment procedure involves using mathematical and CAE tools in the regular class work, homework, mini and term ending projects and possibly in the examinations. However, it should be understood that such tools should be used to supplement theory and concepts covered in the class. Students of the current generation seem to be more inclined to use such tools to generate several 'what if' scenarios during their learning process. Math and CAE tools have been used extensively in all the three courses mentioned here and also by many educators world wide. Overall conclusions are presented below with a suggested assessment procedure.

\section{Conclusions}

Based on the previous experiences of teaching the same classes, in this paper, it can be reiterated that an integration of the math and CAE tools along with assignment of several mini-projects seems to be an effective way for better understanding of the course material. Validation of computer models and results by hand calculations is imperative that the students must realize. Three sample courses, namely, Machine Design, Numerical Analysis, and Dynamic Systems and Control taught at three different universities by three different instructors to different set of students confirm the findings of this study. Sample assessment form is presented in this paper that contains the evaluation and assessment of the data collected in a particular term.

As before, students seem to like the group projects and found open ended problems challenging. Such studies can be extended to other engineering courses for their assessment and for continuous improvement of both the course material and performance by the students taking such classes.

\section{Bibliography}

1. R. Echempati, E. Mahajerin, A. Sala "Effective Integration of Mathematical and CAE Tools in Engineering", paper \# AC 2008- 697, Proc. of ASEE 2008 Conference.

2. Proceedings of ASEE Conferences, 2005-2008.

3. UG/I-DEAS ${ }^{\circledR}$ - Siemens: http://www.ugs.com/

4. Mechanical Design of Machine Elements and Machines: A Failure Prevention Perspective, Collins, J. A., Staab, G. H., and Busby, H. R., John Wiley and Sons, 2008.

5. Machine Design: An Integrated Approach, Norton, R. L., Prentice-Hall, 2007.

6. Mechanical Engineering Design, Shigley, Mischke and Budynas, McGraw-Hill, $7^{\text {th }}$ Edition, 2007.

7. Fundamentals of Machine Component Design, Juvinall and Marshek, John Wiley, $4^{\text {th }}$ Edition, 2007Applied Numerical Methods with MATLAB ${ }^{\circledR}$ for Engineers and Scientists, Steven C. Chapra, McGraw-Hill, 2005.

8. Introduction to MATLAB ${ }^{\circledR}$ for Engineers, W. J. Palm III, Wiley, 2001.

9. Gnanapragasam, N., et al. "Comparison between Grade Earned in a Course and Performance in a simulated FE examination for Mechanics Related Courses", paper \# AC 2008- 2854, Proc. of ASEE 2008 Conference.

10. Hein, G., and Kemppainen, A. "Adopting a Success Strategy for First Year Engineering Students Enrolled in Pre-Calculus", paper \#AC 2008-351, Proc. of ASEE 2008 Conference.

11. Rodriguez, J et al., "Lab Activities to Validate CAE-based Results for Hose Deformations", Paper \# AC 2008-2823, Proc. of ASEE 2008 Conference. 
12. E. Rodriguez-Marek, M.S. Koh, C. Talarico, "Connecting the Dots in Assessment: from Course Student Learning Objectives to Educational Program Outcomes to ABET Assessment", paper \#AC 2008 - 316, Proc. of ASEE 2008 Conference.

13. H. Gurocak, "Direct Measures for Course Outcomes Assessment for ABET Accreditation", paper \#AC 2008 -778, Proc. of ASEE 2008 Conference. 